\title{
BMJ Open Needlestick and sharps injuries in an Indonesian tertiary teaching hospital from 2014 to 2017: a cohort study
}

\author{
Evy Yunihastuti (D) , ${ }^{1,2}$ Dewi Mira Ratih, ${ }^{1}$ Matdoan Rifkiah Aisyah, ${ }^{2}$ \\ Ainum Jhariah Hidayah, ${ }^{2}$ Alvina Widhani, ${ }^{1,2}$ Andri Sanityoso Sulaiman, ${ }^{1}$ \\ Teguh Harjono Karjadi, ${ }^{1,2}$ Czeresna Heriawan Soejono (D) ${ }^{1}$
}

To cite: Yunihastuti E, Ratih DM Aisyah MR, et al. Needlestick and sharps injuries in an Indonesian tertiary teaching hospital from 2014 to 2017: a cohort study. BMJ Open 2020;10:e041494. doi:10.1136/ bmjopen-2020-041494

- Prepublication history for this paper is available online. To view these files, please visit the journal online (http://dx.doi org/10.1136/bmjopen-2020041494).

Received 10 June 2020 Revised 17 November 2020 Accepted 25 November 2020

Check for updates

(c) Author(s) (or their employer(s)) 2020. Re-use permitted under CC BY-NC. No commercial re-use. See rights and permissions. Published by BMJ.

${ }^{1}$ Department of Internal Medicine Faculty of Medicine Universitas Indonesia, Hospital Dr Cipto Mangunkusumo, Central Jakarta, DKI Jakarta, Indonesia

${ }^{2}$ HIV Integrated Unit, Hospital Dr Cipto Mangunkusumo, Central Jakarta, DKI Jakarta, Indonesia

Correspondence to

Dr Evy Yunihastuti;

evy.yunihastuti@gmail.com

\section{ABSTRACT}

Objective Needlestick and sharps injuries among healthcare workers (HCWs) pose significant occupational health problems. We aim to provide incidence and other epidemiological aspects of needlestick and sharp injuries (NSSIs) among HCWs in a tertiary teaching hospital in Indonesia, to inform the evaluation of NSSIs prevention programme.

Methods A cohort study was conducted at Cipto Mangunkusumo Hospital in Jakarta. We analysed data of the sharps injury programme at the hospital between January 2014 and December 2017. Incidence of NSSIs was calculated per 1000 person-years (1000-PY). Results Over the 4-year period, a total of 286 NSSIs were reported. The mean NSSIs incidence rate for 4 years was 13.3/1000-PY, peaking in 2015 (15.5/1000-PY) then decreasing afterward. Most NSSIs were experienced by nurses $(42.7 \%)$, but the highest incidence was among midwives (18.9/1000-PY), followed by nurses, medical students and medical doctors (15.2/1000-PY, 12.6/1000PY and 11.8/1000-PY, respectively). The devices causing the highest proportion of NSSIs were hollow-bore needles (66.8\%), followed by suture needles (14.3\%) and solid needles (10.8\%). 9.4\% of NSSIs were related to insulin pen injection. Of all the incidents, $31.3 \%$ occurred during surgical procedures, $25.9 \%$ during blood collections, $14.3 \%$ during administering injection of drugs and $13.3 \%$ during waste cleaning.

Conclusion In conclusion, this study showed varied incidences of NSSI among different occupations, with the highest among midwives and nurses. Many unsafe work practices still continue, which is of utmost concern. We suggest opportunities for prevention including training and cultivating safer workplace practices.

\section{INTRODUCTION}

Healthcare workers (HCWs) are at greater risk of occupational exposure to needlestick and sharp injuries (NSSIs). Needlestick and sharps injury is defined as the parenteral introduction of blood or other potentially infectious materials by needles or sharp devices, including but not limited to needles, lancets, scalpels and contaminated broken glass used during the performance of their

\section{Strengths and limitations of this study}

- This study research was the first study reporting comprehensive data of needlestick and sharp injuries (NSSIs) in Indonesia.

- The baseline data presented here will allow us to improve the reporting system, considering more safety devices and designing more appropriate NSSI prevention training programmes such as mandatory NSSI induction for regularly changing healthcare workers (HCWs) within the hospital. A national sharps injury surveillance programme is recommended to mitigate risk and assist in policy translation.

- The first limitation of the study was the selfreporting system data. We did not investigate the under-reporting rate, the attitude and work practices of HCWs and other important factors in reporting NSSIs.

- Second, the study was limited a singular tertiary teaching hospital; therefore, the results cannot be generalised to all settings. Nevertheless, this study involved diverse types of HCWs, including cleaning staff members.

duties. ${ }^{1}$ NSSI is sometimes called a percutaneous injury.

Globally, about one in three HCWs are at risk of injury annually. The pooled 1-year prevalence was even higher in low-income and middle-income countries at $36.3 \%(95 \%$ CI $30.3 \%$ to $42.2 \%$ ) and $41.8 \%$ (95\% CI $36.7 \%$ to $46.9 \%$ ) compared with $24.8 \%$ (95\% CI $19.4 \%$ to $30.2 \%$ ) in high-income countries. ${ }^{2}$

Following NSSIs, more than 20 types of bloodborne pathogens can be transmitted. Despite the availability of effective treatments, the possibility of getting HIV, hepatitis $\mathrm{C}$ virus (HCV) and hepatitis B virus (HBV) may lead to HCWs' psychological distress, including depression, anxiety, post-traumatic stress disorder and an impaired quality of life. The estimated transmission rates for HIV, $\mathrm{HCV}$ and $\mathrm{HBV}$ following percutaneous injury 
are $0.2 \%, 1.8 \%$ and $30 \%$, respectively, but only HBV can be prevented by vaccination. ${ }^{3}$ NSSIs generate significant direct costs due to postexposure management, indirect costs such as counselling, staff absence and compensation, further potential costs and intangible costs. ${ }^{14} \mathrm{~A}$ systematic review in 2016 showed that outside from costs for treating infections, the medians of the means were US $\$ 425$ (range 48-1516) for direct costs and US $\$ 322$ (range 152-413) for indirect costs of needlestick injury. ${ }^{4}$

Little is known about the type of incidence of NSSI among HCWs in Indonesia. Available publications were mostly survey studies among particular professions that implied many recall biases. ${ }^{5} 6$ A model developed in 2005 predicted that sharps injuries among HCWs led to an estimated $1445 \mathrm{HBV}$ infections, $399 \mathrm{HCV}$ infections and $18 \mathrm{HIV}$ infections in Indonesia. ${ }^{7}$ Although NSSIs prevention programme is included in standard prevention programmes, national sharps injury surveillance programme is not available and injured workers only voluntarily report the incidence to healthcare authorities, thus masking the true prevalence.

We aim to provide incidence and other epidemiological aspects of NSSIs among HCWs in a tertiary teaching hospital in Indonesia, to inform the evaluation of the NSSIs prevention programme.

\section{METHODS}

This cohort study was conducted at Cipto Mangunkusumo Hospital in Jakarta, the capital of Indonesia. This tertiary care hospital is linked with the Faculty of Medicine, University of Indonesia with a capacity of 1064 beds. We considered that HCWs-including all paid and unpaid persons working in the hospital-have the possibility of exposure to infectious blood and other potentially infectious fluids. Therefore, we included a variety of HCWs such as doctors, nurses, laboratory technicians, medical students, cleaning and other auxiliary staffs.

We analysed data from the hospital sharps injury programme from January 2014 to December 2017. The injured HCWs filled the special forms and were referred to our team for investigation and further assessments. According to the evaluation, investigations of potential HBV, HCV and HIV infections were conducted and postexposure prophylaxis were started immediately as needed. The form incorporates questions on HCWs' demographic, locations of injury, type of devices used, circumstances leading to injury, actions taken immediately after injuries and description of possible sources of infection. In order to avoid bias, we used a form that was standardised and designed for occupational postexposure prophylaxis programme. HCWs have to report and complete the form within 24 hours after injury.

We included age, sex, exposed place, reporting time and source patient's bloodborne infection status in the descriptive analysis. Incidence of NSSIs was calculated per 1000 HCWs per year. The total number of HCWs per year was obtained from the hospital and the Faculty of Medicine's human resource department and grouped into doctors, nurses, medical students, midwives, laboratory technicians, pharmacists and cleaning staffs. SPSS V.23.0 (SPSS) was used for the analysis and Microsoft Excel was used for graphics. HCWs who did not complete the form were excluded in this study.

Verbal informed consents were obtained. We informed the participants that personal identifiers were anonymised prior to data processing for confidentiality.

\section{Patient and public involvement}

Patients and public were involved in the conduct and dissemination plans of our study research.

\section{RESULTS}

Over the 4-year period (2014-2017), there was an average of 7760 HCWs yearly with a total of 286 NSSIs who all completely filled the form and reported the incidence. Table 1 shows that the majority of NSSI cases occurred in the hospital wards $(37.1 \%)$ and emergency room $(26.2 \%)$, followed by the operating theatre $(15.7 \%)$. Three cases occurred in the hospital morgue facility (1\%). The source patient's bloodborne infection statuses were mostly unknown $(63.5 \%$ for HIV, $65 \%$ for $\mathrm{HBV}$ and $65.7 \%$ for HCV). In the remaining NSSIs, the source patients were most frequently represented by HIVinfected patients in 31 cases $(10 \%)$ and less frequently by HBV-infected patients (16 cases, 5.6\%) and HCV-infected patients (16 cases, $5.6 \%$ ).

The mean NSSIs incidence rate for 4 years was 13.3 per 1000 person-years, increasing in 2015 (15.5 per 1000 person-years), then declining afterwards (table 2). Of all reported cases, most NSSIs were experienced by nurses $(42.7 \%)$, followed by doctors $(38.5 \%)$. However, the highest incidence rate was found to be among midwives (18.9 per 1000 person-years) as seen in figure 1 .

Table 3 shows the types of needles and sharps devices related to NSSIs. The devices associated with the highest proportion of NSSIs were hollow-bore needles (66.8\%), followed by suture needles $(14.3 \%)$ and solid needles $(10.8 \%)$. Syringe needles were the most common hollow-bore needle-related injuries $(45.5 \%)$. Insulin pen injection-related incidents had the same proportion with catheter-stylet-related incidents $(9.4 \%)$. Lancets that are used to examine blood glucose levels also caused notable number of NSSIs in the hospital (10.1\%).

Of all reported cases, $45.8 \%$ occurred when using the devices, $40 \%$ before and $12.3 \%$ during disposal of devices. Of all the incidents, 31.3\% occurred during surgical procedures, $25.9 \%$ during blood collections, $14.3 \%$ during administering drug injections and 13.3\% during waste cleaning. Recapping practices resulted in only $5.9 \%$ of all NSSIs (table 4 ).

\section{DISCUSSION}

Accidental injuries with needles or other sharps are still common among HCWs. Although the risks of developing HIV, HBV, and HCV are small, the consequences 
Table 1 Epidemiological characteristics of needlestick and sharps injuries among healthcare workers during 2014-2017 $(n=286)$

\begin{tabular}{lc}
\hline Feature & N (\%) \\
\hline Healthcare workers characteristics & \\
Gender & \\
$\quad$ Male & $90(31.5)$ \\
\hline Female & $196(68.5)$ \\
\hline Age & \\
\hline$<30$ years & $166(58.0)$ \\
\hline $30-40$ years & $87(30.4)$ \\
\hline $40-50$ years & $21(7.3)$ \\
\hline$>50$ years & $9(3.1)$ \\
\hline No data & $2(0.7)$ \\
\hline Exposed place & $106(37.1)$ \\
\hline Ward & $75(26.2)$ \\
\hline Emergency room & $45(15.7)$ \\
\hline Operating room & $29(10.1)$ \\
\hline Laboratory & $27(9.4)$ \\
\hline Ambulatory clinic & $3(1)$ \\
\hline Morgue & $256(89.5)$ \\
\hline Reporting time & $30(10.5)$ \\
\hline Within 24 hours & \\
\hline More than 24 hours & \\
\hline Source patient: bloodborne infection status \\
\hline Vstatus
\end{tabular}

HIV status

\begin{tabular}{cc} 
Positive & $31(10.8)$ \\
Negative & $73(25.5)$ \\
Unknown & $182(63.6)$ \\
\hline HBV status & \\
\hline Positive & $16(5.6)$ \\
Negative & $84(29.4)$ \\
Unknown & $186(65)$ \\
\hline HCV status & \\
\hline Positive & $14(4.9)$ \\
\hline Negative & $84(29.4)$ \\
Unknown & $188(65.7)$ \\
\hline
\end{tabular}

$\mathrm{HBV}$, hepatitis $B$ virus; $\mathrm{HCV}$, hepatitis $\mathrm{C}$ virus.

of these occupational injuries are serious and worrisome. This present study was conducted at the tertiary teaching hospital in Indonesia to investigate the incidence of voluntarily reported NSSIs and the first in Indonesia to provide real data on NSSIs.

Overall incidence of NSSIs in this study was 13.3 injuries per $1000 \mathrm{HCWs}$-years. Our result is considered low compared with many other reports. Other studies in Singapore, Korea, Turkey, Poland and Germany have reported higher incidence rates of between 19 and 45 per
$1000 \mathrm{HCWs}^{8-12}$ However, a study evaluating data from the Malaysian national sharps injury surveillance programme estimated the incidence of NSSIs was 6 injuries per 1000 HCWs, lower than our study. ${ }^{13}$ These conflicting results might be due to different settings, study designs, and methods for injury reporting. However, since our data were based on a voluntary reporting system, we acknowledge the issue of unreported NSSIs, which might undercalculate the true incidence of NSSIs in our hospital. The unwillingness to report any work-related injuries was still common among HCWs. The under-reporting rates estimated in other studies vary between $42 \%$ and $95 \% .^{10} 14-16$ There are several reasons for not reporting injuries: (1) a lack of awareness regarding the reporting system or of the need to report NSSIs, for fear of getting into trouble, (2) concerned about being perceived as lacking clinical skills, (3) embarrassment, (4) perception that the extent of the injury was light or having antibodies conferring protection against disease and (5) dissatisfaction with follow-up investigations by officials after reporting the events. ${ }^{16-19}$ Further studies are warranted to define the real incidence of NSSIs in our institution, as well as possible reasons for under-reporting, and to find a new and appropriate reporting system to reduce this under-reporting situation.

It was not surprising that the significant number of injuries were reported by nurses $(42.7 \%$ of total reported case, incidence 15 per 1000 nurses-years). As a common pattern of studies around the world, nurses were more likely to get NSSIs than other professions. ${ }^{1011141520}$ Due to the nature of nursing work, nurses spend more hours in direct contact with the patients and undertake more procedures with hollow-bore needles as the most common device related to NSSIs. ${ }^{21}$ Nurses are usually responsible for blood collection, administering drug injections and venipuncture, which are also common circumstances for NSSIs in our study $(14.3 \%, 25.9 \%$ and $6.6 \%$, respectively), as well as disposing sharp devices. Although in our study, midwives had the highest incidence rate of NSSIs, this finding needs to be interpreted cautiously as it was probably a trend of increasing reportable injuries among an average of 66 midwives in the hospital. However, special training for prevention needs to be addressed in this group since midwives are also likely to have more contact with blood and body fluids during delivery. Apart from managing delivery, midwives have similar duties as nurses such as phlebotomy and drug administration to patients. In Indonesia, midwives' education programme is not a continuation of the general nursing programme. However, training on infection control standards are included during orientation programmes within the hospital.

In the present study, NSSIs occurred most commonly during surgical procedures $(31.3 \%)$, followed by blood collection $(25.9 \%)$. Stitching with suture needles contributed to $14.3 \%$ of NSSIs, as a majority of incidents were in surgical room (table 4). Our data correspond with studies in Malaysia, Singapore and Egypt. ${ }^{1322} 23$ In a study by Ishak et al, stitching injuries were found to be the 
Table 2 Needlestick and sharps injury rate and risk according to professions and years (2014-2017)

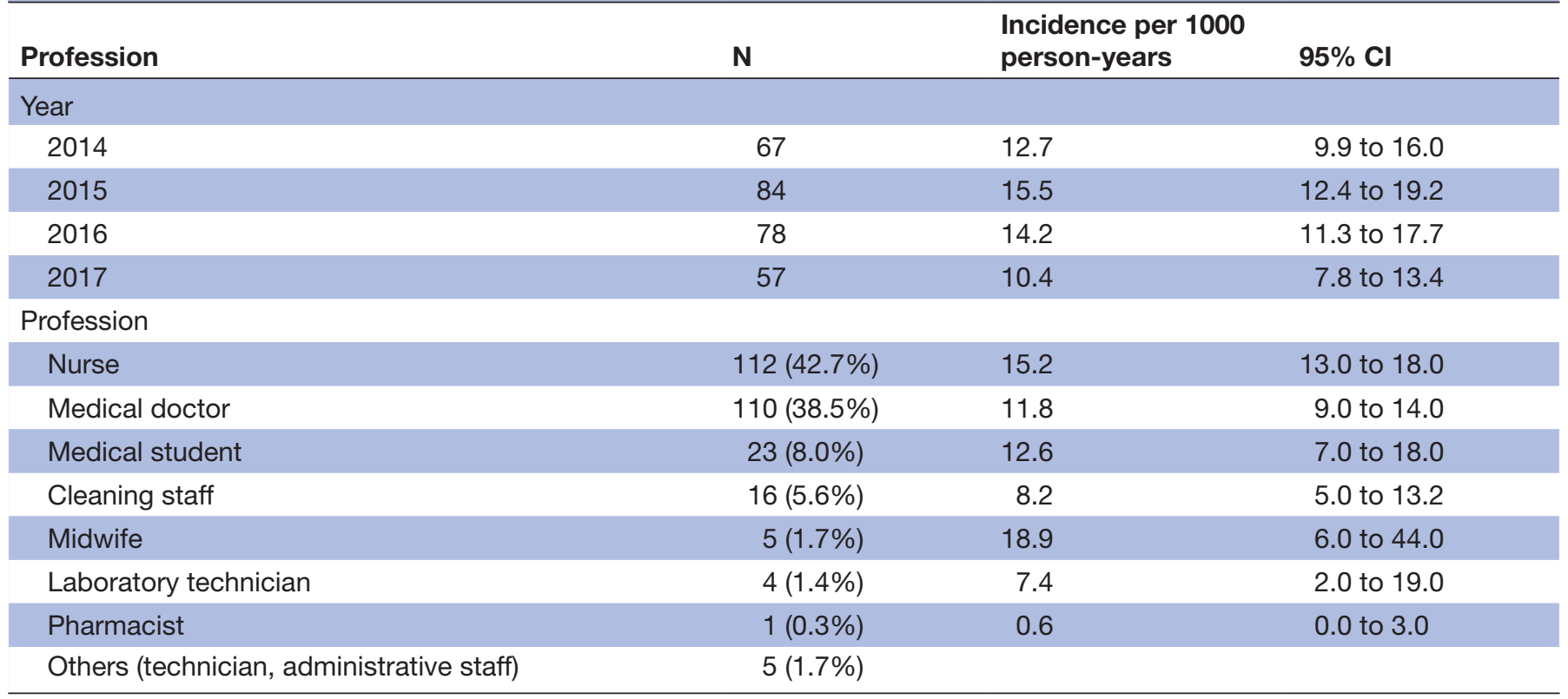

result of being stuck with needles placed at inappropriate locations, being stuck with a needle during a collision, related to equipment disposal, or accidentally dropped equipment. ${ }^{13}$

Another event category that contributed to NSSIs includes injuries during waste cleaning $(13.3 \%)$, whether by cleaning staff or other professions. The number of injuries occurring during this process depended on the number of needles and sharp devices in the area, as well as the incorrect disposal behaviour by the original users of the items. ${ }^{24}$ Cleaning staff members in our hospital were outsourced from other companies, hence it was inevitable that personnel changed regularly. Strict controls need to be implemented to properly dispose of needles and sharps device waste.
The majority of the injuries were largely due to hollowbore needle injuries $(66.7 \%)$, mainly disposable syringes $(45.5 \%)$, which is consistent with the results of many previous studies. ${ }^{14202325}$ Recapping practices resulted in some NSSIs in our study. Due to limited resources at the hospital, safety-engineered devices (SEDs) were rarely used.

The use of insulin cartridge delivery pens have widely replaced traditional syringe injection since it was introduced in the 1990s. Despite its many benefits, including ease of use and transport, greater dose accuracy and reduction to needle phobia, this type of NSSI in HCWs in a hospital setting is now increasing. Our study indicated that $9.4 \%$ of NSSIs in the hospital were related to insulin pen injections. A recent survey among hospital nurses

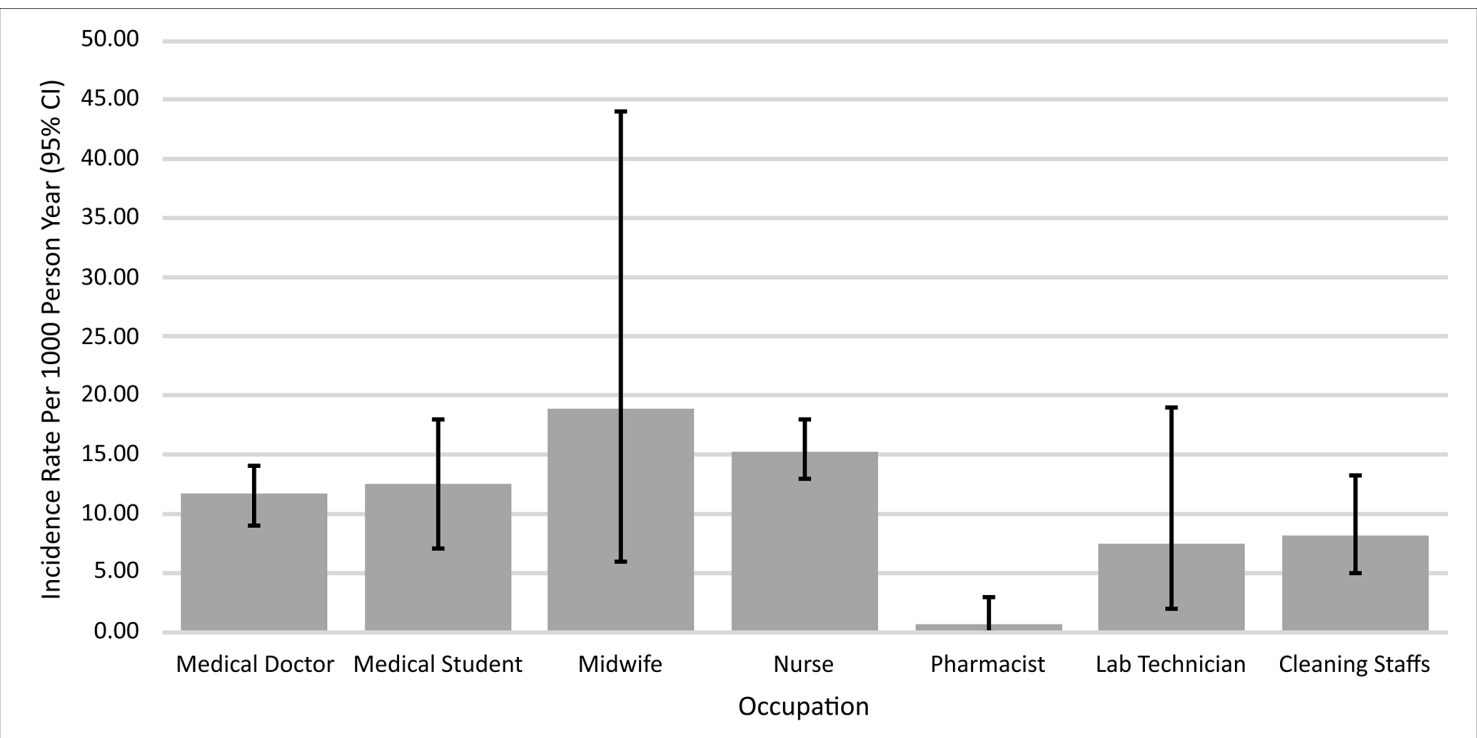

Figure 1 Incidence rate of needlestick and sharps injuries according to occupation (per 1000 person-year). 
Table 3 Types of needle and sharp devices related to injury

\begin{tabular}{lc}
\hline Types of needle and sharp devices & N (\%) \\
\hline Hollow bore & $191(66.8)$ \\
\hline Syringe needle & $130(45.5)$ \\
Catheter stylet & $27(9.4)$ \\
\hline Insulin needle & $27(9.4)$ \\
Butterfly wing & $5(1.7)$ \\
Electromyography needle & $1(0.3)$ \\
\hline Endodontic needle & $1(0.3)$ \\
\hline Suture needle & $\mathbf{4 1 ( 1 4 . 3 \% )}$ \\
Solid needle & $31(\mathbf{1 0 . 8} \%)$ \\
Glucose stick lancet & $29(10.1)$ \\
Other solid needle & $2(0.7)$ \\
\hline Scalpel & $\mathbf{2 0}(\mathbf{7 . 0 \% )}$ \\
\hline Others (glass, sharp tool) & $\mathbf{3 ( 1 . 0 \% )}$ \\
\hline
\end{tabular}

in China reported that the incidence of insulin pen injection-related NSSI was 10.2 per 100000 injections. About $40 \%$ of nurses experienced at least one insulin pen injection-related NSSIs sometime in the past. ${ }^{26}$ An increasing prevalence of diabetes in Indonesia will have implications on insulin pen injection-related NSSIs in the future. In addition, the use of finger prick lancets for blood glucose monitoring in our hospital also caused a significant number of NSSIs (10.1\%). Recently, a study in Malaysia also observed that other non-specific tasks $(14 \%)$ such as finger prick for blood glucose monitoring or cleaning of devices were important causes of NSSI. ${ }^{22} \mathrm{~A}$ pilot implementation study for the use of SED lancets in South Korea demonstrated a promising result in reducing the lancet-related NSSIs to zero incidence. ${ }^{27}$

However, not all application of needles with an SED will result in a decrease of NSSIs, as shown in a recent study

\begin{tabular}{lc}
\hline $\begin{array}{l}\text { Table } 4 \text { Circumstances leading to needlestick and sharps } \\
\text { injuries }\end{array}$ & N (\%) \\
\hline Circumstance & \\
\hline Time & $131(45.8)$ \\
\hline Use device & $115(40.2)$ \\
\hline Before disposal & $38(12.3)$ \\
\hline Device disposal & $2(0.7)$ \\
\hline Not related to any procedure & \\
Event & $74(25.9)$ \\
\hline Blood Collection & $41(14.3)$ \\
\hline Administering injecting drug & $19(6.6)$ \\
\hline Venipuncture & $17(5.9)$ \\
\hline Recapping & $89(31.3)$ \\
\hline Surgery/non-surgical procedure & $38(13.3)$ \\
\hline Waste cleaning & $8(2.8)$ \\
\hline Others (not related to medical procedure)
\end{tabular}

in the Netherlands and a systematic review by Reddy et $a l .^{28}{ }^{29}$ Findings from previous meta-analysis evaluating effectiveness of different interventions for NSSIs prevention concluded that the most effective intervention is a combination of safety training and proper use of SED. ${ }^{30}$ Moreover, provision of feedback to the manufacturers to keep improving the design is critical. ${ }^{28}$

The results of our study should be interpreted in the context of study limitations. The most important limitation was that the data was based on a self-reporting system. We did not investigate the under-reporting rate, the attitude and work practices of HCWs, and other important factors in reporting NSSIs. However, since this is the first study reporting comprehensive data of NSSIs in Indonesia, the baseline data presented here will allow us to improve the reporting system, considering more safety devices and designing more appropriate NSSI prevention training programme for regularly change HCWs within the hospital. Since the introduction of electronic health record system in our hospital, incorporating NSSI reporting system into this electronic system would be the most pragmatic approach. Hopefully sharps injury registry will soon be initiated by policy-makers at a national level.

The study was also limited to situation in tertiary teaching hospital; therefore, the results cannot be generalised to other settings. Nevertheless, this study involved diverse types of HCWs, including cleaning staff members.

\section{CONCLUSIONS}

In conclusion, this study showed varied incidences of NSSIs among different occupations, with the highest incidence rates among midwives and nurses. The continued presence of many unsafe practices remain an important concern that needs further training in order to provide a safer workplace for HCWs. Further research on overall reporting processes and qualitative evaluation is needed in designing a prevention programme to reduce NSSIs. A national sharps injury surveillance programme should be recommended to mitigate the risk of NSSIs and assist in policy translation.

Acknowledgements Acknowledgments were given to patient advisers, all staff, residents, and nurses who work at HIV Integrated Unit, Cipto Mangunkusumo Hospital, Jakarta, Indonesia.

Contributors EY and DMR designed the study. EY and MRA wrote the manuscript. EY and DMR did data acquisition. EY and AJH analysed and interpreted the data. All authors read and approved the final manuscript. AW, ASS, THK and CHS revised the paper critically.

Funding The authors have not declared a specific grant for this research from any funding agency in the public, commercial or not-for-profit sectors.

Competing interests None declared.

Patient and public involvement Patients and/or the public were involved in the design, or conduct, or reporting, or dissemination plans of this research. Refer to the Methods section for further details.

Patient consent for publication Not required.

Ethics approval This study was approved by the Ethical Committee of Faculty of Medicine, Universitas Indonesia and local permission was acquired from the 
authority of Cipto Mangunkusumo Hospital. Protocol number of this study was 18-01-0013 and ID of ethical approval was 0020/UN2.F1/ETIK/2018.

Provenance and peer review Not commissioned; externally peer reviewed.

Data availability statement Data are available on reasonable request.

Open access This is an open access article distributed in accordance with the Creative Commons Attribution Non Commercial (CC BY-NC 4.0) license, which permits others to distribute, remix, adapt, build upon this work non-commercially, and license their derivative works on different terms, provided the original work is properly cited, appropriate credit is given, any changes made indicated, and the use is non-commercial. See: http://creativecommons.org/licenses/by-nc/4.0/.

\section{ORCID iDs}

Evy Yunihastuti http://orcid.org/0000-0001-6650-0559

Czeresna Heriawan Soejono http://orcid.org/0000-0003-4968-4936

\section{REFERENCES}

1 Rapiti E, Prüss-üstün A, Hutlin Y. Sharps injuries: assessing the burden of disease from sharps injuries to health-care workers at national and local levels. Geneva: World Health Organization, 2005. https://apps.who.int/iris/bitstream/handle/10665/43051/924159232X. pdf? sequence $=1$ \&isAllowed $=y$

2 Auta A, Adewuyi EO, Tor-Anyiin A, et al. Global prevalence of percutaneous injuries among healthcare workers: a systematic review and meta-analysis. Int J Epidemiol 2018;47:1972-80.

3 Beltrami EM, Williams IT, Shapiro CN, et al. Risk and management of blood-borne infections in health care workers. Clin Microbiol Rev 2000;13:385-407.

4 Mannocci A, De Carli G, Di Bari V, et al. How much do needlestick injuries cost? A systematic review of the economic evaluations of needlestick and sharps injuries among healthcare personnel. Infect Control Hosp Epidemiol 2016;37:635-46.

5 Silowati T, Handiyani H, Rachmi SF. Prevention behavior for NSI among nursing students and nurses in Indonesia: a comparative study. Enferm Clin 2019;29 Suppl 2:803-7.

6 Handiyani $\mathrm{H}$, Meily Kurniawidjaja L, Irawaty D, et al. The effective needle stick injury prevention strategies for nursing students in the clinical settings: a literature review. Enferm Clin 2018;28 Suppl 1:167-71.

7 Agustian D, Yusnita S, Susanto $\mathrm{H}$, et al. An estimation of the occupational risk of HBV, HCV and HIV infection among Indonesian health-care workers. Acta Med Indones 2009;41 Suppl 1:33-7.

8 Seng M, Sng GKJ, Zhao X, et al. Needlestick injuries at a tertiary teaching hospital in Singapore. Epidemiol Infect 2016;144:2546-51.

9 Lee JH, Cho J, Kim YJ, et al. Occupational blood exposures in health care workers: incidence, characteristics, and transmission of bloodborne pathogens in South Korea. BMC Public Health 2017; $17: 827$.

10 Garus-Pakowska A, Górajski M. Epidemiology of needlestick and sharp injuries among health care workers based on records from 252 hospitals for the period 2010-2014, Poland. BMC Public Health 2019;19:634.

11 Çiçek-Şentürk G, Tekin A, Gürbüz Y, et al. Retrospective investigation of 9 years of data on needlestick and sharps injuries: effect of a hospital infection control Committee. Am J Infect Control 2019;47:186-90.

12 Fritzsche C, Heine M, Loebermann M, et al. Reducing the underreporting of percutaneous exposure incidents: a single-center experience. Am J Infect Control 2016;44:941-3.

13 Ishak AS, Haque MS, Sadhra SS. Needlestick injuries among Malaysian healthcare workers. Occup Med 2019;69:99-105.

14 Huang S-L, Lu Q, Fan S-H, et al. Sharp instrument injuries among hospital healthcare workers in mainland China: a cross-sectional study. BMJ Open 2017;7:e017761.

15 Martins A, Coelho AC, Vieira M, et al. Age and years in practice as factors associated with needlestick and sharps injuries among health care workers in a Portuguese Hospital. Accid Anal Prev 2012;47:11-15.

16 Pervaiz M, Gilbert R, Ali N. The prevalence and underreporting of needlestick injuries among dental healthcare workers in Pakistan: a systematic review. Int J Dent 2018;2018:1-14.

17 Black Thomas LM. Underreporting of bloodborne pathogen exposures in nursing students. Nurse Educ 2020;45:78-82.

18 Azadi A, Anoosheh M, Delpisheh A. Frequency and barriers of underreported needlestick injuries amongst Iranian nurses, a questionnaire survey. J Clin Nurs 2011;20:488-93.

19 Cui Z, Zhu J, Zhang X, et al. Sharp injuries: a cross-sectional study among health care workers in a provincial teaching hospital in China. Environ Health Prev Med 2018;23:2.

20 Memish ZA, Assiri AM, Eldalatony MM, et al. Risk analysis of needle stick and sharp object injuries among health care workers in a tertiary care hospital (Saudi Arabia). J Epidemiol Glob Health 2013;3:123-9.

21 Phillips EK, Conaway M, Parker G, et al. Issues in understanding the impact of the needlestick safety and prevention act on hospital sharps injuries. Infect Control Hosp Epidemiol 2013;34:935-9.

22 Leong XYA, Yee FZY, Leong Y-Y, et al. Incidence and analysis of sharps injuries and splash exposures in a tertiary hospital in Southeast Asia: a ten-year review. Singapore Med J 2019;60:631-6.

23 Hanafi MI, Mohamed AM, Kassem MS, et al. Needlestick injuries among health care workers of University of Alexandria hospitals. East Mediterr Health J 2011;17:26-35.

24 Bianco V, Spera AM, Maraolo AE, et al. Risk of professional accidental exposure to biological agents in health care workers: a retrospective analysis carried out in a southern Italian tertiary hospital. Infez Med 2019;27:40-5.

25 Bekele T, Gebremariam A, Kaso M, et al. Factors associated with occupational needle stick and sharps injuries among hospital healthcare workers in bale zone, Southeast Ethiopia. PLoS One 2015;10:e0140382

26 Zhao F, Zhang M, Xuan J, et al. Burden of insulin injection-related needlestick injuries in mainland China-prevalence, incidence, and healthcare costs. Int J Nurs Stud 2019;97:78-83.

27 An HS, Ko S, Bang JH, et al. Elimination of lancet-related needlestick injuries using a safety-engineered Lancet: experience in a hospital. Infect Chemother 2018;50:319-27.

28 Schuurmans J, Lutgens SP, Groen L, et al. Do safety engineered devices reduce needlestick injuries? J Hosp Infect 2018;100:99-104.

29 Reddy VK, Lavoie M-C, Verbeek JH, et al. Devices for preventing percutaneous exposure injuries caused by needles in healthcare personnel. Cochrane Database Syst Rev 2017;11:CD009740.

30 Tarigan LH, Cifuentes M, Quinn M, et al. Prevention of needle-stick injuries in healthcare facilities: a meta-analysis. Infect Control Hosp Epidemiol 2015;36:823-9. 